\title{
EDUCAÇÃO PRUSSIANA LIBERAL: A GÊNESE HISTÓRICA DO MODELO MILITARISTA DE EDUCAÇÃO NO TOCANTINS
}

\author{
PRUSSIAN LIBERAL EDUCATION: THE HISTORICAL GENESIS \\ OF THE MILITARIST MODEL OF EDUCATION IN TOCANTINS
}

\author{
Tomaz Martins da Silva Filho ${ }^{1}$ \\ José Damião Trindade Rocha ${ }^{2}$ \\ Jocyléia Santana dos Santos ${ }^{3}$
}

\begin{abstract}
RESUMO: O presente trabalho disserta sobre a história do modelo prussiano de educação, como chega ao Brasil e suas influências sobre a militarização da escola pública no estado do Tocantins. Para isso, faz apanhado histórico do surgimento do modelo prussiano de educação. Tem como objetivo entender as justificativas para implantação do colégio militar do Tocantins, percebendo a influência do prussianismo. A metodologia utilizada é a história oral, que aqui assume papel elementar. Os resultados apresentados constatam que a disciplina é algo substancial na educação prussiana, presente na escola militar não somente para com os alunos, mas também com funcionários.

PALAVRAS-CHAVE: Narrativas orais, História da educação, Militarismo, Disciplina prussiana.
\end{abstract}

\begin{abstract}
The present work discusses the history of the prussian model of education, how it arrives in Brazil and its influences on the militarization of the public school in the state of Tocantins. For that, it makes historical record of the emergence of the prussian model of education. Its objective is to understand the justifications for the implementation of the military college of Tocantins, perceiving the influence of prussianism. The methodology used is the oral history, that assumes here elementary role. The results presented show that the discipline is something substantial in the prussian education, present in the military school not only towards students, but with employees too.
\end{abstract}

KEYWORDS: Oral narratives, History of education, Militarism, Prussian discipline.

\footnotetext{
1 Mestrando em Educação PPGE/UFT. Esp. Em Filosofia e Ensino de Filosofia, Licenciado em Filosofia. Professor de Filosofia do Instituto Federal de Educação, Ciência e Tecnologia do Pará - IFPA. Atualmente faz parte da comissão de extensão e do comitê técnico científico desta instituição.

2 Doutor em Educação/UFBA. Mestre em Educação Brasileira/UFG. Diretor de Tecnologias Educacionais DTE/Reitoria/UFT. Coordenador de mestrado Profissional do PPGE/UFT e Docente na Universidade Federal do Tocantins - UFT.

3 Doutora em História pela Universidade Federal de Pernambuco (2006). Mestra em História pela Universidade Federal de Pernambuco (1996). Graduada em Historia pela Universidade Católica de Goiás (1991). É Avaliadora Institucional e de Curso do MEC/ INEP. Atualmente é professora associada da Fundação Universidade Federal do Tocantins, Coordenadora do Programa de Pós-Graduação em Educação (PPGE) da UFT/CAPES.
} 


\section{Introdução}

O modelo militar de educação tem se disseminado por todo o Brasil a partir dos ideais de excelência, disciplina e competitividade. É o modelo de escola pública que o estado idealiza para si, com poucos gastos, menos indisciplina e alunos bem treinados para as avaliações externas, aumentando os índices desejados. Nessa esteira, a militarização da escola pública no Brasil segue uma expansão vertiginosa.

O que se chama de militarização da escola é a implantação do modelo de formação de soldados na escola pública. Esse modelo segue a tradição prussiana de educação militar. Sua característica principal é ter fins utilitaristas de cunho liberal.

A educação prussiana é liberal porque tem como objetivo fundamentar o adestramento das consciências, imprimir a produtividade capitalista e a competitividade. Chama-se prussiana por ter origem na Prússia no séc. XVIII. No Brasil, o mencionado movimento é implantado mecanicamente, pouco importando o caráter dialógico da educação.

Assim, faz-se necessário perceber os fundamentos históricos da educação prussiana liberal e suas implicações no colégio militar do Tocantins. As memórias contidas nas narrativas dos pioneiros desta instituição esclarecem as intenções do prussianismo na mencionada instituição. Portanto, este trabalho questiona quais as justificativas para a implantação de um colégio militar no Tocantins. Deseja, deste modo, compreender as intenções, significados e justificativas da referida instituição.

Este empreendimento terá como base pesquisa bibliográfica, a qual estabelecerá análise crítica da gênese histórica da origem da educação militar.

A partir do conceito de uma educação pública com fins disciplinares estatais, será feito um apanhado das narrativas orais, usando, portanto, da metodologia de história oral que segundo Albert (2004, p. 30), “o emprego da história oral significa voltar a atenção para as versões dos entrevistados. Isso não quer dizer que se possa prescindir de consultar as fontes já existentes sobre o tema escolhido". Por isso a história oral constitui importantíssima metodologia neste trabalho, enquanto a bibliográfica assume o esforço de compreender a gênese histórica do modelo prussiano. Nesse enlace de história escrita e oral brota o valor da entrevista.

E o que é a entrevista documenta enquanto resíduo de ação? Em primeiro lugar, ela é um resíduo de uma ação interativa: a comunicação entre entrevistado e entrevistador. Tanto um como o outro tem determinadas ideias 
sobre seu interlocutor e tenta desencadear determinadas ações, seja fazer com que o outro fale sobre sua experiência (do lado do entrevistador), seja fazer com que o outro entenda o relato de tal forma que modifique suas próprias convicções enquanto historiador (do lado do entrevistado). (ALBERT, 2016).

Deste modo, a metodologia deste artigo se deu na vivência do cotidiano do entrevistado. É uma história que está sendo e que não somente foi. O que se chama resíduo da ação é a memória viva do entrevistado durante o discurso, na hora da entrevista; é ação presente e não somente passado.

Neste panorama a pesquisa teve como entrevistados a $\mathrm{sr}^{\mathrm{a}}$ Cecília Maria de Oliveira Silva, coordenadora de recursos tecnológicos, o sr. Abner Gomes Brelais Junior, assistente administrativo. São os pioneiros da implantação do colégio militar do Tocantins.

\section{História e Narrativas de uma Educação Disciplinar}

Em história da educação há estreita relação entre disciplina e ensino. Essa associação remonta à antiguidade, quando ainda não se falava em escola socialmente instituída, nem em sua gratuidade. Todavia, a disciplina prussiana é o ápice do método disciplinar como instrução.

Assim, a história da disciplina na educação foi justificada de modo significativo quando toda a estrutura antiga e medieval ruiu diante do progresso da razão. $\mathrm{O}$ renascimento do pensamento grego fez surgir uma nova visão de mundo: a modernidade.

A educação moderna estabelece como prioridade a "formação do cidadão, de um indivíduo ativo na sociedade e inserido na organização da comunidade estatal." (CAMBI, 1999, p. 211), com o objetivo de servir à indústria nas grandes revoluções industrial e francesa.

Por esse viés é que na Prússia o último Frederico Guilherme "promoveu a fundação de 1.800 novas escolas em seu reino e até mesmo providenciou uma pequena doação para sua efetivação".(EBY, 1976, p. 274). A escola é o meio mais eficaz para controle das massas na modernidade, sendo "dessa época a descoberta da disciplina; uma disciplina constante e orgânica, muito diferente da violência de uma autoridade não respeitada." (CAMBI, 1999, p. 206). A lei, o rei e a moral são os mantenedores da ordem. 
Essa ordem estabelecida na modernidade percebe o conhecimento como algo acumulativo, em perene progresso. Assim, o processo educacional deve produzir efeitos imediatos, que são: suprir as necessidades burocráticas do Estado e sustentar a indústria nascente com trabalhadores dóceis e disciplinados. Por este motivo foi que

Frederico Guilherme III continuou a reorganização após a guerra, e fortificou o sistema de educação estatal obrigatório em 1834 tornandoo necessário para a entrada de jovens para as profissões liberais, como também todos os candidatos a cargos públicos e os estudantes universitários deveriam passar nos exames de graduação do ensino médio. Deste modo, o estado prussiano obteve controle efetivo sobre todas as gerações vindouras de acadêmicos e outros profissionais. (ROTHBARD, 2013, p. 35)

A obrigatoriedade da educação pública só pode ser sustentada com a disciplinarização da sociedade e do educando, o que levou o "sistema educacional prussiano a ser estendido para o resto da Alemanha [por meio] do decreto de 1872 fortalecendo o controle absoluto do estado sobre as escolas." (ROTHBARD, 2013, p. 36).

À escola prussiana "foram atribuídos um papel ideológico: ela se torna agente da reprodução social e, em particular, da ideologia dominante, do poder e de seus objetivos, seus ideais e sua lógica.” (CAMBI, 1999, p. 207). Essa ideologia é disseminada por meio da disciplina militar, tendo em vista que, "estava em renascimento e grande expansão o exército, em particular a instituição do serviço compulsório militar universal". (ROTHERBARD, 2013, p. 35)

O militarismo não só colaborou para frequência obrigatória das crianças à escola pública, mas também fez com que o próprio modelo educacional tivesse fins militares. A educação prussiana é militarista à medida que educa por meio da disciplina externa.

É prudente dizer que na educação militar há uma vocação para a tecnicidade e o cientificismo, dando seguimento à estrutura do militarismo que padroniza valores a serviço da competitividade burguesa.

Especificamente, o fomento da competitividade torna inviável a educação liberal como modelo universal de educação, pois nem todos podem se equiparar em status de igualdade para competir entre si, criando assim a desigualdade social dentro da escola. Com esses ideais a educação prussiana liberal disciplinar se dissemina por outros países da Europa, tais como França, Inglaterra, Áustria e principalmente Portugal e suas colônias. 
No Brasil (então colônia de Portugal) o prussianismo disciplinar chega com as reformas do Marquês de Pombal. É importante dizer que o liame de Pombal com a pedagogia prussiana liberal se deu pela influência da corte da Imperatriz Maria Teresa da Áustria, onde assume missão diplomática em 1744. Maria Teresa implantará o sistema prussiano em seu país e Pombal está envolto no iluminismo romano-germânico da imperatriz.

O marquês de Pombal, Sebastião José de Carvalho e Melo, primeiramente Conde de Oeiras, é o grande expoente iluminista na política. Segundo Aranha (2006, p. 175), ele é "o grande gestor da introdução das ideias iluministas, agiu com rigor na reforma no ensino". É por isso que se diz que foi com as reformas pombalinas que

a renovação espiritual finalmente chega a Portugal. Para remover o
tradicionalismo, causador de todo o atraso português, o ministro tomou várias
medidas drásticas, dentre elas submeter ao Estado a hierarquia religiosa.
(NIELSEN NETO, 1988, p. 277).

São essas reformas que possibilitam a chegada do prussianismo educacional ao Brasil. Toda reforma é a intenção de uniformizar o deformado, disciplinar determinada realidade. No âmbito estatal as reformas se dão por meio de leis. É deste modo que a reforma da educação colonial se impõe pelo Alvará de 28 de Junho de 1759.

Este importante documento suprime a influência da Companhia de Jesus no sistema educacional de Portugal e colônias, implantando as aulas régias. Esse é o primeiro passo da reforma,

\begin{abstract}
quando as aulas se confiaram aos religiosos jesuítas, em razão de que estes, com o obscuro e fastidioso método, introduziram nas Escolas destes Reinos e seus domínios com exaurível tenacidade com que procuraram sustentá-lo contra as mais puras verdades, que lhe descobriram os desfeitos e os prejuízos desse método. (PORTUGAL, 1759, p. 673)
\end{abstract}

O modelo implantado pelos jesuítas foi substituído pelas aulas régias ${ }^{4}$ (latim, grego, filosofia e retórica) e se opunham às explicações religiosas, às superstições e explicações da escolástica.

$\mathrm{Na}$ prática, a crítica de Pombal aos jesuítas é mais política que realmente metodologicamente educacional. Os jesuítas se tornaram poderosos tanto no meio secular como eclesiástico. Fizeram inimigos fora e dentro da cúria romana, o que levou à supressão da ordem religiosa e sua expulsão da maioria dos países.

\footnotetext{
$4 \quad$ As aulas régias eram o ensino elementar das humanidades e a implantação da educação pública em Portugal e colônias.
} 
Após a expulsão dos Jesuítas, o conde de Oeiras, que em 1769 se torna Marques de Pombal, faz famoso discurso sobre a esperança que tem no Estado português:

O desenvolvimento da cultura geral, o incremento das indústrias, o progresso das artes, o progresso das letras, o progresso científico, a vitalidade do comércio interno, a riqueza do comércio externo, a paz política, a elevação do nível de riqueza e o bem-estar. (SAVIANI, 2011, p. 81)

Essa é a noção de progresso do Estado moderno. Despotismo esclarecido que Pombal compartilha com Frederico Guilherme I. A perspectiva de desenvolvimento das artes, da ciência, das humanidades só deve ter uma finalidade: o bem-estar e a elevação do nível de riqueza. A educação é a via mais eficaz para fazer progredir o comércio, tanto interno como externo, pois somente homens bem instruídos serão ordeiros, politizados e bons comerciantes.

Deste modo, a reforma pombalina visa ter três princípios básicos: (1) a escolástica dos jesuítas seria substituída pelo pensamento pedagógico da escola pública e laica, (2) a criação do cargo de diretor de estudos, visando à fiscalização do ensino e (3) a introdução de aulas régias.

Essa tríade compunha o projeto prussiano liberal, outrora traçado. Primeiramente, a instituição da escola pública, pelo fato de todos os indivíduos terem obrigação de servir ao Estado e para bem servi-lo, deveriam ser instruídos. Segundo, a implantação e a fiscalização desse modelo devem ser de ordem estatal e não mais da Igreja. Afinal "Emancipa-se dos modelos religiosos-autoritários do passado, visa a formação de um homem como cidadão, capaz de ser faber fortunae." (CAMBI, 1999, p. 326). O homem moderno é dono de seu próprio destino, é faber fortunae, fabrica sua própria sorte. Ademais, o terceiro princípio é a implantação das aulas régias, que nada mais é do que as condições de possibilidade para o homem se tornar dono de seu próprio destino. Em conjunto trata-se de disciplinar o sistema de ensino.

Essas aulas exigiam dinheiro, demanda de professores, bibliotecas de primeiríssimo mundo, doutores em filosofia, latim, grego e ciências. A coroa não estava disposta financeiramente a gastar com tantos. Ao menos, não gastou como deveria com as colônias. É um projeto fracassado, pois tirou o pilar da educação brasileira colonial, os jesuítas, e nada colocou no lugar. É perceptível o vácuo deixado pelos padres em Portugal e consequentemente Brasil. 
Surge nesse cenário o Subsídio Literário, um imposto criado por um Alvará de 10 de Novembro de 1772. O objetivo era custear as reformas no campo da instrução pública. É preciso lembrar que para o rei de Portugal era

\begin{abstract}
impossível adotar-se um plano que permitisse estender os benefícios do ensino a todos igualmente, pois nem todos os indivíduos deste reino e seus domínios se hão de educar com destino aos estudos maiores [...] ficam excluídos deste destino os empregados nos serviços rústicos e nas artes fabris, que ministram os sustentos dos povos e constituem os braços e mãos do Corpo Político. (SAVIANI, 2011, p. 95- 96)
\end{abstract}

No Brasil, especificamente, a impossibilidade de execução do subsídio literário torna sem efeito qualquer progresso descrito anteriormente por Pombal. Nem se fala em indústria, desenvolvimento científico e concurso de mestres para aulas régias. $\mathrm{O}$ sistema é extremamente precário.

Há um hiato de 1772 a 1808, pois somente neste ano, com a fuga da família real, é que chegam as primeiras instituições de ensino, bibliotecas e cursos superiores técnicos. A educação superior no Brasil e o planejamento da educação básica começam a surtir efeitos por conta da inversão de relações políticas metrópole-colônia. Somente em 1823 com a constituinte, é que chega ao Brasil o modelo educacional revolucionário francês, advogando o direito a educação por meio do Sufrágio Universal.

O Brasil já é um país independente de Portugal, mas na educação pública não obtém sucesso. O tão almejado progresso prussiano liberal não se mostra vigoroso na jovem nação independente. Tiveram diversas tentativas de implantação da escola pública: em 15 de outubro de 1827 se faz lei própria para o ensino que também não prospera. Os primeiros cursos superiores criados no Brasil (Olinda e São Paulo) são da área técnica, desvalorizando a educação básica. A Constituição da Mandioca em 1834 piora a situação da educação básica. Com o ato adicional, a constituição passou o ensino e instrução superior ao encargo das províncias. Não deu certo, pelo fato de as províncias serem demasiadamente pobres.

Dado o fracasso dos projetos do governo de implantação de escola pública de qualidade no Brasil, temos que destacar a presença e preocupação dos militares com esse aspecto da sociedade.

O ensino militar enquanto formação de soldados, o que chamamos de discentes de farda, é algo presente desde o início do Brasil colônia, mas somente com o fracasso do ensino público é que esse modelo de formação de soldados é transplantado, ou inicialmente cogitado para formação de civis. 
Em 1840, o Regente Araújo Lima, Marquês de Olinda, procurou estabelecer, por meio de decreto, um colégio para os filhos necessitados dos capitães e oficiais subalternos, no Arsenal de Guerra da Corte: o "Colégio Militar do Imperador". A ideia foi nobre, mas não chegou a se tornar uma realidade (BRASIL, 2015, p. 10).

Os militares sempre estiveram neste país envolvidos com assuntos de política civil. Porém, o Marquês de Olinda se preocupou especificamente com os filhos de Capitães e oficiais subalternos. É uma preocupação recorrente no modelo prussiano liberal. Aqui a educação prussiana mostra-se capaz de mudar no decorrer do processo histórico, passando do modelo técnico-científico civil para o militarista.

É bom lembrar que Frederico I, quando pensa a primeira escola militar, fá-la para filhos de militares e com finalidades militaristas. Aqui permanece o ideal burguês de seguir a tradição familiar de carreira dos pais. No século XIX e XX, também se pensará as escolas militares com essa finalidade. Então, o Duque de Caxias, Luís Alves de Lima e Silva

\begin{abstract}
Em 1853, apresentou um projeto ao Senado, criando um Colégio Militar (CM) na Corte. Não conseguiu convencer os seus pares e a iniciativa não prosperou. O mesmo Caxias, em 1862, insistiu, novamente, na criação de uma Escola " [...] que amparasse os órfãos, filhos de militares da Armada e do Exército que participaram na defesa da Independência, da Honra Nacional e das Instituições". Mais uma vez, o desejo não se concretizou. (BRASIL, 2015, p. 10).
\end{abstract}

Após as negativas ao projeto do Duque de Caxias, o primeiro colégio militar no Brasil foi criado ainda no império em 25 de abril de 1888. Seu objetivo era a educação assistencial no Rio de Janeiro. É criado o Colégio Militar do Rio de Janeiro - CMRJ.

É bom lembrar que o ensino militar, em um período de apatia educacional, onde o sistema público é quase falido, faz suscitar um ideal de homem: o herói nacional. Esse ideal deve ser seguido copiosamente, por isso "o aluno assimila os valores de obediência, submissão, dependência, paternalismo, assiduidade, pontualidade, racionalidade e meritocracia." (LUDWIG, 1998, p. 22). Todavia, somente em 07 de janeiro de 1919, o Governo Federal, por meio da lei № 3674, criou o Colégio Militar do Ceará juntamente com quatro estabelecimentos, quando por razões políticas, o $\mathrm{CM}$ de Barbacena foi extinto. Em 1925 seus servidores foram distribuídos para outras organizações do Exército. Em 1938, também são extintos o Colégio Militar do Ceará, restando apenas o Colégio Militar do Rio de Janeiro.

Em 1956, o Estado Maior elaborou o plano que previa a construção de vários colégios militares nas capitais brasileiras, entre elas Curitiba, que só foi implantado em 
1959, criado por decreto no período de governo de Juscelino Kubitschek (1956-1960) e com aperfeiçoamentos arquitetônicos e pedagógicos em 1964.

Há destaque significativo na educação com a primeira Lei de Diretrizes e Bases -LDB de 1961, que pouco tempo depois se depara com o jugo militar em 1964. Neste período o sistema prussiano liberal atinge seu período mais explícito no Brasil. A disciplina militar, a obediência quase religiosa ao professor e ao Estado golpeado pelos militares são marcas indeléveis da disciplina prussiana. Dado o enfraquecimento do governo militar e a constituinte de 1988 (cem anos após a criação do primeiro colégio militar), o ensino prussiano é mantido no país, inicialmente destinado à formação de jovens rapazes, filhos de militares, posteriormente para filhos de civis.

Hoje em âmbito nacional, existem os colégios militares do Exército, gerenciados pela DEPA, atualmente a Diretoria de Educação Preparatória e Assistencial, é o órgão de apoio técnico-normativo do Departamento de Educação e Cultura do Exército DECEx. Existem os colégios militares do corpo de bombeiros, ligados a cada unidade federativa, assim como os colégios da polícia militar.

A partir desses dois modelos a implantação dos colégios militares no Brasil se dissemina. 1955: Criação do Colégio Militar de Belo Horizonte; 1957: Colégio Militar de Salvador; 1959: Colégio Militar de Recife; 1962: Reabertura dos Colégios Militares de Porto Alegre e Fortaleza (antigo Colégio Militar do Ceará); 1971: Criação do Colégio Militar de Manaus; 1978: Criação do Colégio Militar de Brasília.

A DEPA gerencia 13 colégios por todo o território nacional. Colégio Militar de Belém (CMBel), localizado em uma das principais avenidas de Belém, a Almirante Barroso, foi fundado no dia 12 de janeiro de 2016; Colégio Militar de Belo Horizonte $(\mathrm{CMBH})$, que surgiu a partir do colégio militar de Barbacena em 1912. No dia 12 de setembro de 1955, o Presidente da República, Café Filho, assinava o Decreto n ${ }^{\circ} 37.879$, que criou o Colégio Militar de Belo Horizonte; Colégio Militar de Brasília (CMB), criando através do Decreto 81.248, de 23 de janeiro de 1978, do Presidente da República, General do Exército Ernesto Geisel; Colégio Militar de Campo Grande (CMCG), criado pela Portaria Ministerial no 324 de 29 de junho de 1993, iniciou suas atividades escolares em 06 de fevereiro de 1995; Colégio Militar de Curitiba (CMC), sobre o qual já tratamos anteriormente; Colégio Militar de Fortaleza (CMF), antigo colégio militar do Ceará e que fora extinto em 1938 e reinstalado em 1989; Colégio Militar de Manaus (CMM), inaugurou suas atividades em 7 de abril de 1972; Colégio Militar de Juiz de Fora (CMJF) fundado em 1993, por Itamar Franco e Coronel Souto; 
Colégio Militar de Porto Alegre (CMPA), foi criado pelo Decreto $\mathrm{n}^{\circ}$ 9.397, de 28 de fevereiro de 1912; Colégio Militar de Recife (CMR), fundado em 11 de dezembro de 1959, pelo Decreto $n^{\circ}$ 47.416, iniciou seu primeiro ano letivo em 25 de abril de 1960; Colégio Militar de Salvador (CMS), Criado em 05 de abril de 1988; por fim o Colégio Militar de Santa Maria (CMSM), fundado em 22 de março de 1994.

Assim como cada unidade federativa tem autonomia para criar e gerir sua segurança pública e consequentemente sua polícia militar, criam-se os chamados CPM's - Colégios de Polícia Militar, gerenciados em sua maioria, pelos quartéis da polícia militar e não pelas secretarias de educação. É um modelo educacional que se dissemina por todo o país paralelo ao modelo convencional.

Em Palmas, Tocantins, a mais jovem capital no país, também foi fundado o Colégio Militar de Palmas - CMP em 18 de agosto de 2009, uma parceria da Polícia Militar do Tocantins - PM/TO com a Secretaria de Educação e Cultura - SEDUC. Sua missão: contribuir para a educação de jovens tocantinenses, visando um ensino de qualidade e a formação integral e profissionalizante.

Sobre a origem do colégio militar em Palmas-TO é necessário investigar as intenções para sua implantação, visto que em outros estados os motivos foram diversos. Alguns justificados pela autoridade estatal sem qualquer participação popular, outros em consenso com a sociedade civil. Como se viu, a sua maioria foi criada por decretos.

É certo que a história documentada não consegue narrar todos os meandres do surgimento dessas instituições, que são prussianas por excelência. Assim, foi necessário colher relatos orais dos pioneiros da educação militar do Tocantins. a fim de saber as intenções que fomentaram o surgimento do colégio militar. Quando se perguntou sobre os motivos para criação do colégio, a resposta foi:

A polícia queria um ensino de qualidade, até porque eles tinham filhos. Assim, pensando como era sucesso em outros estados aqui também deveria ser. O colégio militar estava dando resultado em outros estados e como eles tem academia dentro do quartel, então foi surgindo a ideia e amadurecendo até que então resolveram implantar. (SILVA, 2016)

Ora, se observarmos bem a justificativa dada, a narrativa oral e a história escrita oficializada em nada discordam. Porém, é válido lembrar que os motivos de implantação de um colégio militar no Tocantins seguem uma tradição bem específica. Esta tradição remonta ao prussianismo de Frederico I (um colégio para filhos de militares) e ao Brasil imperial: uma educação de qualidade, dado o fracasso das demais instituições. O motivo é sempre um heroísmo redentor. Vem sempre para salvar o 
processo educacional que está perdido. Esses são os mesmos motivos usados para implantação de novos colégios militares em quase todas as situações no Brasil.

Com esse intuito, os documentos oficiais da escola dizem que o CMP iniciou sua história ainda no prédio da Quadra 403 sul, com 240 alunos matriculados nos três cursos profissionalizantes, sendo: Técnico em Informática com ênfase em Rede de Computadores, Técnico em Instrumento Musical e Técnico em Trânsito com ênfase em Educação, com cursos gratuitos para militares e comunidade em geral, nas modalidades de Ensino Médio Integrado a Educação Profissional. O que sobressai do discurso da entrevistada (SILVA, 2017) é que "Pegaram um prédio sem uso, ocioso, pegaram essas salas, e nos forneceram. Foi muita correria porque não tinha carteiras, não tinha nada. Tínhamos que buscar tudo em outros colégios.” E ainda (BRELAIS JUNIOR, 2016) diz que: "eles pegaram um armazém e transformaram em um colégio. O que seria o colégio militar. Com a demanda foi que sondaram um novo espaço."

O poder público não forneceu a estrutura adequada para a implantação dessa instituição. Somente desejou sua implantação e o fez de qualquer modo. Então se questiona: qual a urgência de um colégio militar? O Colégio Militar no Tocantins foi uma aposta política: se os objetivos surtissem efeitos, ele continuaria.

A comunidade, como sempre, não é consultada. É uma questão de Estado, visto que os frutos ideológicos são colhidos pelo poder ideológico desse mesmo Estado.

É tanto que apesar da regularidade do ensino, a vocação do colégio militar é técnica: "Tinha o regular, mas a visão mesmo era para formar técnicos. Eram técnicos em informática, instrumento musical e trânsito. Só que trânsito não vingou, ficou só informática e instrumento musical.” (BRELAIS JUNIOR, 2016). O ensino técnico sempre esteve atrelado ao prussianismo e ao militarismo, principalmente por gerar mão de obra barata e irreflexiva para o mercado de trabalho. É o que na modernidade chamase de súditos leais e trabalhadores dedicados.

A ideia de um colégio militar é tão bem aceita pela população e por políticos que, em 2010 o então deputado Osires Damaso requer a extensão do Colégio Militar na Região Sul do Tocantins, justificando que a educação das escolas militares tem grande reconhecimento por parte da população, ressaltando que a intenção é a de direcionar a oportunidade para uma região carente na área educacional. Porém, o pedido não foi atendido. A oposição não veio do gabinete do governador, mas principalmente do corpo pedagógico da secretaria de educação do estado, que vê no militarismo uma 
administração paralela a sua, pois é preciso lembrar que dentro do quartel há uma secretaria de educação e esta gerencia os colégios militares.

Para estabilizar o desgaste, foi assinado um Termo de Cooperação Técnica entre SEDUC/Polícia Militar do Estado do Tocantins, por meio de uma estratégia, na época, tida como inovadora de gestão e operação de ações consorciadas entre a SEDUC/TO e a $\mathrm{PM} / \mathrm{TO}$ onde a SEDUC/TO cedeu à infraestrutura do CEM/Palmas para uso exclusivo de oferta de Cursos Técnicos de Nível Médio, nas modalidades de Educação Profissional articulado de forma integrada e PROEJA (anos finais), permanecendo na Escola Estadual da $403 \mathrm{Sul}$ a oferta do Ensino Fundamental do $6^{\circ}$ ao $9^{\circ}$ ano, sendo delegada competências aos Diretores que assumiram as unidades de ensino, designados pela $\mathrm{PM} / \mathrm{TO}$ para gerir os recursos financeiros e responder pela gestão das Unidades Escolares (UE). Assim, a marca das escolas militares, do pondo de vista administrativo, é que a gestão é sempre de um militar.

Os interesses para a implantação de um colégio militar em Palmas nem sempre são tão claros como foram em outros estados do Brasil. Mas aqui, com as narrativas orais algo se desvela, visto que, a narrativa oral suscita o não dito no texto escrito:

Ele [colégio militar] foi fundado em Agosto, mas bem antes o Tenente Elder, se não me engano hoje ele é Major, ele tem uma visão bem grande de educação, Ele e o Coronel Clóvis. Começaram a fazer pesquisa e viram possibilidade da capital ter um colégio militar, visitaram Goiânia e Recife. Entraram com um pedido para o governador e foi concedido. (BRELAIS JUNIOR, 2016).

O Colégio foi criado em Agosto, no meio de um ano letivo. Atrelam sua história ao Centro de Ensino Médio de Palmas. Mas o fato é que a história deste último quase nada tem a ver com a Escola Militar. O CEM de Palmas tinha uma funcionalidade e o colégio militar foi fundado em outro local. Só após perceberem o êxito do projeto militarista é que se resolve fundir as duas instituições. O CEM de Palmas, segundo narrativa de (Junior, 2016) "estava fechando, só tinha umas 3 turmas, já estava fechando, ninguém queria vir pra cá por causa da localização". Por isso, só em 12 de abril de 2013 é aprovada a mudança de denominação do Centro de Ensino Médio de Palmas para Colégio da Polícia Militar do Estado do Tocantins através da Resolução No 65. “Art. $1^{\circ}$ Aprovar a mudança de Denominação do Centro de Ensino médio de Palmas para Colégio da Polícia Militar do Estado do Tocantins, situado em Palmas, Capital.” (TOCANTINS, 2013). O que se nota, mais uma vez, é que há sempre uma justificativa salvacionista de realidades. Um poder heroico autoinstituído. 
No sentimento heroico está implícito o desejo de superioridade, o arraigamento das tradições militares, a sentimento de pertença a uma casta privilegiada. Isso se nota nas disposições para a competitividade dos alunos entre eles mesmos, do colégio militar com as demais instituições. Ao perguntar à entrevistada sobre o que diferencia o colégio militar de outras instituições de ensino, ela responde:

\footnotetext{
não se desfazendo dos outros colégios, que a gente sabe que faz um bom trabalho. Mas o diferencial aqui é a disciplina que é mantida com respeito. Leva-se o respeito ao outro. A gente fala para o aluno: você tem seus direitos, mas respeitando o do outro. Você tem uma disciplina com regras respeitadas e combinadas. Porque no início do ano aqui agente tem um encontro com os alunos e pais, uma semana antes dos outros alunos chegarem, daí são passadas todas as regras [...] é repassado todas as regras, ele sabe tudo que pode não pode fazer. (SILVA, 2016),
}

Penso que aqui há um afunilamento deste trabalho. Na fala da entrevistada há o ápice da entrevista, a justificativa social para implantação desse modelo: a disciplina. $\mathrm{Na}$ aula inaugural, momento a que se refere a entrevistada, é entregue um caderno com todas as prescrições disciplinares preestabelecidas. É o que ela chama de "repassado todas as regras". Essas normas asseguram o sucesso da instalação do colégio militar em Palmas, sua manutenção. Apesar das divergências pedagógicas na secretaria de educação, a escola militar detém poder ideológico dentro e fora dela. Esse domínio ideológico se dá com o consentimento da máquina estatal que se ver desobrigada dos traumas disciplinares nos quais incorre a educação pública.

\section{Considerações Finais}

No arcabouço de qualquer narrativa está a memória. E na memória da criação dos colégios militares está presente esse desejo heroico salvacionista de uma dada realidade considerada defasada e ineficiente. Não é diferente no colégio militar de Palmas, ou em qualquer outra instituição de ensino militar, principalmente porque segue o modelo liberal prussiano como se percebe no dissertado no percurso histórico aqui descrito.

A aplicabilidade de métodos que visam resultados muito específicos é característica do cartesianismo que molda o modelo prussiano liberal. Na pedagogia militar, o método é a disciplina e os resultados, a obediência. O que não fica explícito nos documentos escritos e nem na história oficial é que há uma pré-seleção do público, há uma indução às regras e à sua obediência e quem não as obedece é excluído. 
Somente uma análise histórica que vá além do simples positivismo lógico pode fazer transparecer essas nuances.

O que se tentou fazer nestes escritos foi desvelar o velado pela formalidade da disciplina, da história formal, do logicamente aceito. Dissertar sobre o escrito nos documentos e confrontá-los com as narrativas orais é, sobretudo, refletir sobre o dito e não dito. Dissertar sobre sua relação com o escrito não é apenas dizer o que falou o entrevistado, mas desvelar o escondido, o suspenso.

Percebe-se, portanto, que os entrevistados nem sempre se sentem a vontade para falar com autenticidade. É compreensível, pois faz parte de um sistema de disciplina. Eles também são disciplinados. Todavia, dar voz ao disciplinado já é o primeiro passo para se fazer história. Esse é o papel da história oral.

\section{Referências}

ALBERTI, Verena. Manual de História Oral. Rio de Janeiro: FGV, 2004.

O que documenta a fonte oral? Possibilidades para além da construção do passado. Disponível em <http:http://cpdoc.fgv.br/producao_intelectual/arq/869.pdf $>$. Acesso em 13 de Dezembro de 2016.

ARANHA, Maria Lúcia de A. História da educação e da Pedagogia Geral e Brasil. 3 Ed. São Paulo: Moderna, 2006.

BRASIL. Projeto Politico Pedagógico: Sistema de Colégio Militar do Brasil. Diretoria de Educação Preparatória e Assistencial. 2015.

CAMBI, Franco. História da pedagogia. tradução de Álvaro Lorencini.São Paulo: Fundação Editora da UNESP, 1999.

CELETI, Filipe Rangel. Origem da educação obrigatória: um olhar sobre a Prússia. Revista Saber Acadêmico. São Paulo, n 13, p. 29 -32, junho/2012.

CPM, Colégio da Polícia Militar. Projeto Político Pedagógico. Palmas. 2016.

BRELAIS JUNIOR, Abner Gomes. Entrevista concedida a Tomaz Martins da Silva Filho. Palmas, 08-12-2016

EBY, Frederick. História da educação moderna: teoria, organização e práticas educacionais. $2^{\text {a }}$ ed. Porto Alegre: Globo. 1976

LUDWIG, Antonio Will Carlos.de Morais. Democracia e Ensino Militar. São Paulo. Cortez 1998.

NIELSEN NETO, H. Filosofia da educação. São Paulo: Melhoramentos, 1990 
PORTUGAL. Alvará de 28 de junho de 1759. Alvará, por que V. Majestade há por bem reparar os Estudos das Línguas Latina, Grega, e Hebraica, e da Arte da Retórica, da ruína a que estavam reduzidos; e restituir-lhes aquele antecedente lustre $<$ http://www.unicamp.br/iel/memoria/crono/acervo/tx12.html $>$ Acesso em: 12-12-2016.

ROTHBARD, Murray N. Educação: livre e obrigatória. Trad. Filipe Rangel. São Paulo: Cele Mises, 2013.

SAVIANI, Dermeval. História das ideias pedagógicas no Brasil. Coleção Memória da educação. 3. ed., Autores Associados. Campinas - SP. 2011.

SILVA, Cecília Maria de Oliveira. Entrevista concedida a Tomaz Martins da Silva Filho. Palmas, 23-11-2016.

TOCANTINS (estado), Resolução $n^{\circ} 65$ de 12 de abril de 2013. Aprova a mudança de denominação do Centro de Ensino médio de palmas para Colégio da polícia militar do Estado do Tocantins, palmas, Capital. Disponível em:

http://www.buscaoficial.com/c/diario/cD6AcndCo/ Acesso: 01 jan 2017.

Recebido em 25/02/2017

Aceito em 26/07/2017 